\title{
TESTAMENTO POR MEIO ELETRÔNICO: É POSSÍVEL?
}

\section{Ana Lúcia Alves Feliciani}

\section{INTRODUÇÃO}

Entre os antigos, o direito de propriedade deitava suas raízes na religião, “tendo-se estabelecido para efetivação de um culto hereditário, não podia extinguir-se ao cabo da vida curta do indivíduo”. ${ }^{1}$ A religião determinava que os bens e o culto de cada família seriam inseparáveis, enquanto o cuidado dos sacrifícios, ou seja, as oferendas sobre o túmulo passavam sempre àquele a quem a herança revertia, qual seja, ao herdeiro. ${ }^{2}$ Isso porque a religião doméstica era "hereditária, de varão em varão, a propriedade igualmente o era”. ${ }^{3}$

Embora isso, primitivamente, o testamento não era conhecido, tendo em conta que o direito de testar achava-se em conflito com as crenças religiosas, as quais eram a base do direito de propriedade e do direito de sucessão. ${ }^{4} \mathrm{E}$ isso era assim, porque a propriedade não pertencia ao indivíduo, mas, sim, à família, sendo que aquela era adquirida pelo culto doméstico e não pelo trabalho.

Dentre os Romanos, anota Fustel de Coulanges que o "testamento não era absolutamente desconhecido, mas, na prática, muito difícil. Exigiam-se-lhe, grandes formalidades”. No entanto, na época das XII Tábuas, “o testamento aparece sob a forma de uma declaração proclamada entre a assembleia do povo, os comícios curiatos (testamento comicial) ou perante os

1 COUlAngES, Fustel de. A Cidade Antiga. Trad. de Fernando Aguiar. São Paulo: Martins Fontes, 2000, p. 69.

2 Ibidem.

3 Ibidem.

4 Idem, p. 79. 
companheiros de armas (testamento militar)". ${ }^{5}$ John Gilissen aponta, ademais, que a literatura jurídica da época clássica, em matéria de sucessão, é "quase exclusivamente consagrada ao testamento, não se ocupando senão muito acessoriamente da sucessão $a b$ intestato", ${ }^{6}$ sendo certo que "sob o Império, o testamento romano tornou-se um acto relativamente simples: pode ser feito por uma declaração oral (nuncupatio) diante de sete testemunhas, pela qual o testador institui um herdeiro". ${ }^{7}$ O testamento era, pois, "il negozio di gran lunga piú importante nella vita socialie e giuridica in Roma", ${ }^{8}$ podendo ser definido como “quell'atto solenne di ultima volontà col qualse si nomina l'erede e si può trimenti del próprio patrimônio per legato, nominare tutori, manomettere servi, ecc.". ${ }^{9}$

É certo, nesse viés, que o direito sucessório romano, consagrado nas Institutas de Justiniano, solidificou os parâmetros do direito das sucessões, que norteia o Direito Sucessório pátrio da atualidade ${ }^{10}$, 'o qual não é campo aberto a inovações de grande porte, mas, tendo estrita conexão com duas instituições básicas do ordenamento jurídico de qualquer povo, como são a família e a propriedade, é compreensível que receba influência por que estas passam". ${ }^{11}$

Carlos Maximiliano ${ }^{12}$ ensina que “denominam-se atos jurídicos mortis causa os que entram em vigor pelo

5 GILISSEN, John. Introdução Histórica ao Direito. Tradução de A. M. Hespanha e L.M. Malheiros. Lisboa: Fundação Calouste Gulbenkian. 1995, p. 689.

6 Ibidem.

\section{Ibidem.}

8 BONFANTE, Pietro. Instituzioni di Diritto Romano. Torino: G. Giappichelli Editore. 1957, p. 584.

9 Idem, p. 584.

10 Institutas do Jurisconsulto Gaio. Tradução J. Cretellla Jr. Agnmes Cretella. São Paulo: Editora Revista dos Tribunais, 2004, p. 91. Gaio referia que 'havia a princípio dois tipos de testamentos, a saber: as pessoas faziam testamento calatis comitiis, realizados duas vezes por ano e destinados aos que faziam testamentos, ou então, in procintu, quando se preparavam para a guerra, porque procinctus é o exérctio preparado e armado", mas "quem não tinha feito esses dois testamentos [...] e tivesse receio de morrer repentinamente, dava a um amigo seus bens de família, isto é, seu patrimônio em mancipação, especificando o que pretendia dar a cada um, depois da morte. Chama-se par aes el libram e esse tipo de testamento que se faz por mancipação".

11 GOMES, Orlando. Direito das Sucessões. Rio de Janeiro: Forense, 1986.

12 MAXIMILIANO, Carlos. Direito das Sucessões. Rio de Janeiro: Freitas Bastos, 1942, p. 351. 
falecimento do disponente e em regra se aplicam ao espólio do mesmo" de sorte que "a vontade individual se prolonga além da morte e até depois de cessar a capacidade jurídica, embora na generalidade dos casos, o direito sujetivo exista ao serviço e no interesse dos vivos". ${ }^{13}$

O testamento é a espécie de ato jurídico causa mortis que interessa ao presente estudo e trata-se de "ato unilateral, de última vontade, gratuito e solene, contendo disposições patrimoniais ou providência de caráter pessoal ou familiar, exequíveis depois da morte do testador", ${ }^{14}$ cujo "principal objetivo das disposições é substituir, total ou parcialmente, a sucessão legítima, pela voluntária”. ${ }^{15}$

No Brasil, a evolução legislativa relativa ao direito sucessório passa pelas Ordenações do Reino - Ordenações Afonsinas (1446), Ordenações Manuelinas (1521) e Ordenações Filipinas (1603), bem como pela Consolidação das Leis Civis, de Augusto Teixeira de Freitas, de 1859, constituindo-se em verdadeiro Código Civil do período imperial ${ }^{16}$, até a entrada em vigor do Código Civil de 1916, cujo projeto aprovado foi, como se sabe, o elaborado por Clóvis Beviláqua, que vigorou no país até 10 de janeiro de 2002. ${ }^{17}$

O testamento resiste ao tempo, pois, na atualidade, verificada a capacidade e a legitimidade, excluída da legítima dos eventuais herdeiros necessários, bem como observadas as minuciosas solenidades previstas nos artigos 1.857 a 1.896 do Código Civil em vigor, poderá o testador dispor sobre seu patrimônio, bem como sobre questões não patrimoniais, para depois de sua morte.

Há, porém, um número diminuto de pessoas que falecem deixando testamento, em relação àquelas que deixam que a lei estabeleça os herdeiros sucessíveis para receber seu patrimônio, quiçá, pela complexidade das regras que compõem o primeiro modo de sucessão.

Todavia, não se pode perder de vista que "o direito de testar assenta em duplo fundamento - econômico e

\section{Ibidem.}

14 MAXIMILIANO, Carlos, p. 354-355.

15 MAXIMILIANO, Carlos, p. 360.

16 Seguiram-se a Consolidação das Leis Civil, de Augusto Teixeira de Freitas, os anteprojetos de Nabuco de Araújo (1872), Felício dos Santos (1881), Coelho Rodrigues (1893) e Clóvis Beviláqua (1889).

17 Nesse sentido e para estudo detalhado da evolução histórica do Direito Sucessório, remetemos o leitor para a obra de Euclides de Oliveira. Direito de Herança: a nova ordem da sucessão. São Paulo: Saraiva, 2005, p. 15-34. 
moral”"18, pelo que a lei regula a sucessão em conformidade com o pensamento geral e as ideias dominantes em cada país ${ }^{19}$, de sorte que a ideia de disposição de última vontade deve estar adequada à evolução da coletividade. ${ }^{20}$

Nessa linha, o presente estudo busca uma visitação ao direito sucessório, especialmente à sucessão testamentária, de modo a contextualizá-la, em razão das novas tecnologias da informação e da comunicação, à nova configuração da atual sociedade, dita informática, destacando que o Código Civil de 2002 admite a realização do testamento a próprio punho ou por meio mecânico, sem mencionar os meios eletrônicos.

Não pretendemos, no entanto, analisar de forma aprofundada a sucessão testamentária, embora rico o ambiente para tanto, bem como não abordaremos minuciosamente as questões que envolvem a assinatura digital e a certificação digital associada à infraestrutura de chaves públicas brasileira - ICP-Brasil, criada pela Medida Provisória n. 2.200-2, de 24 de agosto de 2001. Bem como não analisaremos detidamente essas questões à luz das disposições da Lei n. 11. 419 de 2006, que dispôs sobre a informatização do processo judicial, mas buscar-se-á promover um diálogo entre os direitos sucessórios, digital, notarial e processual civil, traçando linhas gerais de modo a compatibilizá-los entre si em perspectiva da sociedade pós-moderna. ${ }^{21}$

Para tanto, o estudo será dividido em duas partes. Na primeira, faremos anotações acerca do testamento, apontando seus requisitos essenciais de validade, tal como dispostos no Código Civil em vigor; na segunda, nossa atenção estará voltada para o atual tecido social, marcando características da pós-modernidade, marcada que é, entre outros aspectos, pela sociedade virtual.

18 Ibidem, p. 361.

19 Ibidem, p. 361.

20 Ibidem, p. 362.

21 Antonio Junqueira Azevedo pontua algumas características dos tempos pós-modernos: "a hipercomplexidade, que, no mundo jurídico, se revela na multiplicidade de fontes do direito, quer materiais - porque hoje são vários os grupos sociais, justapostos uns aos outros, todos dentro da mesma sociedade, mas valores compartilhados (shared values), e cada um querendo uma norma ou lei especial para si -, quer formais com um sem-número de leis, decretos, resoluções, códigos deontológicos, avisos etc.” (AZEVEDO, Antonio Junqueira de. O Direito pós-moderno e a codificação. Revista de Direito do Consumidor, São Paulo, v. 9, n. 33, p. 123-129, jan.-mar. de 2000). 


\section{TESTAMENTO}

Sucessão, do latim succedere, significa "vir depois". ${ }^{22}$ Eduardo de Oliveira Leite ${ }^{23}$ ensina que "a palavra 'sucessão' tem duplo sentido na linguagem jurídica. Em sentido próprio (ou restrito) ela designa a transmissão de bens de uma pessoa em decorrência de sua morte. Como transmissão, a sucessão estabelece uma ligação entre duas pessoas”, o autor da herança, também denominado de cujus ${ }^{24}$, e o sucessor. Em sentido lato, sucessão designa o ato pelo qual uma pessoa toma o lugar de outra, substituindo-a no campo das relações jurídicas, havendo apenas alteração de sujeitos, mantendo-se o bem jurídico.

O primeiro sentido é o que interessa ao presente estudo.
A morte determina a abertura da sucessão, ${ }^{25}$ em que a herança transmitese, desde logo, aos herdeiros legítimos ou testamentários. ${ }^{26}$ A sucessão dá-se por lei ou por disposição de última vontade, ${ }^{27}$ de sorte que, na ausência desta, a partilha dos bens segue o critério legal, sendo convocados a suceder os familiares mais próximos, em conformidade com a ordem de vocação hereditária. ${ }^{28}$

A sucessão testamentária vem regulada nos artigos 1.857 a 1.990 do Código Civil em vigor, somando 133 dispositivos. Já à sucessão legítima, o legislador pátrio dedicou apenas 72 artigos, do 1.784 ao 1.856 , o que revela não apenas a importância como também a complexidade, da sucessão testamentária no direito brasileiro.

22 FERREIRA, Aurélio Buarque de Holanda. Novo Aurélio Século XXI: O dicionário da língua portuguesa / Aurélio Buarque de Holanda Ferreira. - 3. ed. rev. e ampl. Rio de Janeiro: Nova Fronteira, 1999, p. 1.897.

23 LEITE, Eduardo de Oliveira. Direito Civil Aplicado. V. 6: direito das sucessões. São Paulo: Editora Revista dos Tribunais, 2004, p. 23.

24 SILVA, De Plácido e. Vocabulário Jurídico. 7. ed. Rio de Janeiro: Forense, 1982. p. 17-18. A locução de cujus é de origem latina, "que se traduz aquele ou aquela de cujo ou de cuja, utilizada não somente para indicar que a sucessão está aberta, como para significar pessoa falecida, sendo assim equivalente a morto, ao falecido, ao sucedido. O uso da expressão advém de uma abreviação feita à frase: De cujus sucessione agitur (aquele de cuja sucessão se trata)".

25 RIZZARDO, Arnaldo. Direito das Sucessões. 4. ed. Rio de Janeiro: Forense, 2008, p. 22.

26 Art. 1.784, Código Civil de 2002.

27 Art. 1.786, Código Civil de 2002.

28 NADER, Paulo. Direito da Sucessões. V. 6. 2. ed. Rio de Janeiro: Forense, p. 194. 
Em que pese reduzida a parcela das pessoas que falecem deixando testamento ${ }^{29}$, Arnaldo Rizzardo, ${ }^{30}$ com propriedade, justifica a grande importância dada pelo Código Civil a essa espécie de sucessão:

Em parte, explica-se o maior realce em vista da liberdade individual que predominava nos tempos de formulação do Direito codificado de 1916 e perdurou, embora com menor intensidade, no Código de 2002.

[...]

Mas há de considerar ainda que o testamento encerra um significado também de ordem social, em que se viabiliza a distribuição das riquezas fora dos círculo restrito dos parentes, às vezes não bastante necessitados quanto um estranho contemplado pelo autor da herança. Muitas pessoas, na verdade, encontram na sucessão testamentária o único caminho de remediar a situação econômica e de serem compensados pela dedicação e desvelo que revelaram ao morto quando vivia.

A par disso, na hipótese de falecer o autor da herança sem deixar descendentes, restando sobrevivente o apenas cônjuge, por meio de disposição testamentária, poder-se-á conservar para este a maior parte do patrimônio, evitando sua pulverização com os ascendentes, especialmente se tais bens são necessários como moradia e para subsistência. ${ }^{31}$ Na ausência de familiares mais próximos, a transmissão da herança a colaterais, quiçá, sem nenhuma relação de afeto com o falecido, pode ser evitada. ${ }^{32}$

O testamento traduz-se em simples meio para a transmissão de patrimônio ${ }^{33}$, podendo veicular disposições de cunho existencial, como, v.g., o re-

29 Eduardo de Oliveira Leite refere, no entanto, que "a regra, no Brasil, desde a Colônia até à República, era a utilização do testamento e a exceção era a morte $a b$ intestato. Mas, mesmo após o advento do Código Civil (de 1916), grande parte da população brasileira continuou se servindo da forma testamentária para manifestação de suas últimas vontades. E no interior do Brasil (onde vive grande parte da população brasileira) o recurso à forma testamentária ainda é muito utilizado”. Ob. cit., p. 178.

30 RIZZARDO, Arnaldo. Ob. cit., p. 227.

31 Ibidem, p. 227.

32 Ibidem, nesse sentido, p. 227.

33 Nesse particular, Orlando Gomes questiona: "Quanto à propriedade, interroga-se mais incisivamente onde identificar sua função social -'ratio' de sua legitimidade - na sua aquisição por herança, que não se funda, como adverte um escritor, nem sobre o trabalho, nem na poupança do adquirente. Resposta não se obtém porque a função social da propriedade é uma ideia estranha à sucessão hereditária como simples transmissão de bens a que se reduz”. Ob. Cit., Prólogo. 
conhecimento de filho ${ }^{34}$, sendo certo que "ao não recorrer ao testamento, o hereditando renuncia o direito de fazer alguns ajustes com a sua quota disponível, para atender a membros da família ou a terceiros, visando retribuir algum benefício especial recebido ou favorecer aos mais necessitados, guiando-se, destarte, por um sentido amplo do valor justiça". ${ }^{35}$

$\mathrm{Na}$ precisa definição de Paulo Nader $^{36}$, "testamento é modalidade de negócio jurídico unilateral, personalíssimo, formal, revogável, mortis causa, cujo objeto é a destinação de bens, para pessoas físicas ou jurídicas, respeitada a quota dos herdeiros necessários, ou disposição de natureza não econômica, expressamente admitida em lei”.

Eduardo de Oliveira Leite $^{37}$, de forma didática e sintética, anota que o testamento reveste-se das seguintes características: (1) é um negócio jurídico; (2) é ato personalíssimo; (3) é ato unilateral; (4) é negócio gratuito; (5) é negócio formal e solene; (6) é negócio jurídico revogável; (7) é negócio jurídico causa mortis.

É negócio jurídico porque o testamento se forma mediante declaração de vontade, cujos efeitos são conferidos pelo ordenamento jurídico; é unilateral porque basta a manifestação de vontade do testador, desde que seja capaz e seja maior de dezesseis anos ${ }^{38}$, é ato personalíssimo ${ }^{39}$ porque sua ideação se deve unicamente ao disponente, não sendo possível que o façam terceiros, por meio de procuração; é gratuito porque ainda que haja disposição de encargos aos beneficiários, não estará afastada tal característica; é formal e solene a fim de garantir o efetivo cumprimento da real vontade do testador; é revogável porque o declarante pode rever suas disposições a qualquer momento antes de sua morte, modificando-as, substituindo-as, ou mesmo afastandoas total ou parcialmente ${ }^{40}$; e é causa mortis porque em sendo válido o testamento, somente terá eficácia com a morte do testador.

34 Art. 1.857, parágrafo segundo, Código Civil de 2002.

35 NADER, Paulo. Ob. cit., p. 195.

36 NADER, Paulo. Ob, cit., p. 203.

37 LEITE, Eduardo de Oliveira. Ob. cit., p. 179.

38 Arts. 1.857 e 1.860, parágrafo único, ambos do Código Civil de 2002.

39 Art. 1.858, Código Civil de 2002.

40 Art. 1.858, Código Civil de 2002. 
A fim de garantir a vontade do testador, a lei civil prevê determinadas formas a serem observadas, sob pena de nulidade do ato, distinguindo-as "por um conjunto de solenidades indispensáveis e insubstituíveis" ${ }^{41}$, que serão objeto de análise no próximo ponto.

\section{A) Formas de Testamento}

O Código Civil de 2002 estabelece as formas ordinárias ou comuns e as especiais de testar. As primeiras estão previstas no art. 1.862, incisos I e III, e referem-se às formas pública, cerrada e particular, são aquelas que "todas as pessoas capazes podem fazer em qualquer circunstância”. ${ }^{42}$ As segundas permitem-se em "circunstâncias extraordinárias e se caracterizam pela dispensa de formalidades exigidas para a validade dos ordinários" ${ }^{43}$. Estas encontram-se dispostas nos incisos I a III do art. 1.886, dispondo sobre o testamento marítimo, aeronáutico e militar. Não se permite, no entanto, a forma híbrida.

Cada uma dessas formas encontra regramento próprio, a par de contar com disposições gerais, comuns a todas, comoacontece com a capacidade para testar ${ }^{44}$ e a impossibilidade de inclusão da legítima dos herdeiros necessários no testamento - ou seja, há limitação à autonomia da vontade, pelo que o testamento deve restringirse à metade da herança -, bem como a possibilidade de disposição testamentária de caráter não patrimonial. ${ }^{45}$

O testamento público guarda como requisito essencial à sua validade a necessidade que seja escrito por tabelião, em conformidade com as declarações prestadas pelo testador, que poderá valer-se de minuta para tanto, bem como que, após lavrado o instrumento, seja ele lido em voz alta pelo serventuário extrajudicial ao disponente e a duas testemunhas, a um só tempo. Por fim, para a conclusão do negócio, o instrumento deve ser assinado por todos

41 GOMES, Orlando. Sucessões. 14. ed. rev., atual. e aumentada de acordo com Código Civil de 2002 por Mario Roberto Carvalho de Faria. Rio de Janeiro: Forense, 2008, p. 100.

42 Idem, p.106.

43 Ibidem.

44 Art. 1.857 e parágrafo único do art. 1.860, Código Civil de 2002.

$45 \mathrm{O}$ reconhecimento de paternidade é hipótese prevista no art. 1.609, mas, nesse ponto, resulta afastado o caráter da irrevogabilidade (art. 1.610). Disposições testamentárias não patrimoniais podem ser, também: a nomeação de tutor pelos pais (parágrafo único do art. 1.729); a reabilitação do indigno (art.1.818); a deserdação (art. 1.964); a nomeação de um ou mais testamenteiros (art. 1.976); sufrágios por alma do falecido (art. 1.998). 
que estiverem presentes no ato. É de notar que essa forma testamentária é a única permitida ao cego (art. 1.867), mas é facultada ao surdo, saiba este ou não ler (art. 1.866).

A forma cerrada vem prevista nos artigos 1.868 e seguintes do Código Civil. Deverá o testamento ser escrito pelo disponente, ou por outra pessoa, ou pelo tabelião, a seu pedido. Após assinado pelo testador, será aprovado pelo tabelião, que lavrará e lerá o correspondente auto de aprovação, tudo na presença de duas testemunhas. Ao analfabeto e a quem não possa ler não é permitido testar na forma cerrada (art. 1.872), mas o é ao surdomudo, desde que o escreva todo e o assine de sua própria mão (art. 1.873).

O testamento hológrafo, particular ou aberto, pode ser escrito de próprio punho ou mecanicamente. É o que dispõe o art. 1.876 do Código Civil. No primeiro caso, deve ser lido e assinado por quem o escreveu; no segundo, deve estar a cédula testamentária a salvo de rasuras ou espaços em branco. Em ambos os casos, deve ser lido na presença de no mínimo três testemunhas, que também o subscreverão, sob pena de resultarem inválidas as disposições testamentárias.
Dentre os especiais, os testamentos marítimo e aeronáutico podem ser deixados por forma que corresponda ao público ou ao cerrado, como também podem ser utilizados por aqueles que estiverem em viagem, a bordo de navio nacional, de guerra ou mercante. O disponente deverá testar perante o comandante, na presença de duas testemunhas, mas caducará o testamento se o testador não morrer na viagem e, ao seu desembarque em terra, não fizer outro testamento na forma ordinária nos 90 dias subsequentes.

Por fim, o testamento militar é possível não apenas aos militares, mas também às pessoas que estejam a serviço das Forças Armadas, quando em campanha, dentro do país ou no exterior, bem como em situação de praça sitiada, com ou sem condições de comunicação. Nessa situação, em não havendo tabelião ou seu substituto legal, o testamento deverá ser feito ante duas ou três testemunhas, se o testador não puder ou não souber assinar, caso em que assinará por ele uma delas. Estando tais pessoas em combate, é possível que testem oralmente, confiando sua última vontade a duas testemunhas. Os parágrafos $1^{\circ}$ a $3^{\circ}$ estabelecem situações ainda mais especiais ${ }^{46}$,

46 Art. 1.893, CC/2002 - § $1^{\circ}$ Se o testador pertencer a corpo ou seção de corpo destacado, o testamento será escrito pelo respectivo comandante, ainda de graduação ou posto inferior. $\S 2^{\circ}$ Se o testador estiver em tratamento em hospital, o testamento será escrito pelo respectivo oficial de saúde, ou pelo diretor do estabelecimento. $\S 3^{\circ} \mathrm{Se} o$ testador for oficial mais graduado, o testamento será escrito por aquele que o substituir. 
em que, escrito o testamento, que poderá ser feito de próprio punho pelo testador, desde que assinado por este, deverá ser entregue ao auditor ou oficial de patente que lhe faça as vezes, igualmente na presença de duas testemunhas.

Ainda que individualmente analisadas, as prefaladas modalidades de testamento guardam em comum a forma escrita - salvo o militar, único que admite feitura oral, quando as pessoas referidas no art. 1.893 estiverem feridas ou em combate (art. 1.896, Código Civil) -, e a necessidade de assinatura do testador, ou a seu rogo, como permitem os testamentos público e cerrado (arts. 1.865 e 1.868).

As assinaturas dos testamentos que "certificam" tradicionalmente a manifestação de vontade do testador serão objeto de nossa análise nas próximas linhas.

\section{B) A manifestação de vontade do testador}

O testamento, negócio jurídico que é, "requer forma escrita para sua validade, sendo que a sua escrituração pode ser feita em qualquer meio e sobre qualquer material, desde que indelével a grafia" ${ }^{47}$, podendo "ser escrito de próprio punho do testador ou por meios mecânicos" ${ }^{48}$

$\mathrm{Na}$ disciplina legal das formas testamentárias referem-se apenas os elementos extrínsecos, atinentes ao modo como o testador deve declarar a sua vontade e ao número, rogação e idoneidade das testemunhas instrumentárias. A chamada forma interna, relativa às condições para testar, é objeto de outras disposições. ${ }^{49}$

Pela ordem disposta no Código Civil, a primeira forma de testamento ordinário é a pública (art. 1.862, I), a qual guarda como requisito essencial a assinatura do testador, do tabelião e das duas testemunhas.Se o primeiro não puder ou não souber assinar, uma das testemunhas instrumentárias poderá assinar a seu rogo ${ }^{50}$ (art. 1.865), o que será declarado pelo tabelião.

O novo Código Civil não exigiu, nessa forma de testamento, a obrigatoriedade de as declarações do testador

47 GOMES, Orlando. Ob. cit., p. 100. 48 Ibidem.

49 GOMES, Orlando. Ob. cit., p. 107.

50 Leonardo Brandelli ensina que "a possibilidade de utilização da assinatura a rogo aplica-se somente ao testador. As testemunhas [...] deverão ser alfabetizadas e estar possibilitadas assinar, caso contrário, deverão ser substituídas”, in (Teoria do Geral do Direito Notarial, São Paulo: Saraiva, 2007, p. 323). 
ser prestadas de viva voz, afastando-se o princípio da oralidade adotado pelo Código de 1916 ${ }^{51}$, permitindo expressamente a possibilidade de utilização de minutas ou apontamentos pelo disponente. Embora a escrituração do testamento seja ato do tabelião, consoante dispõe o parágrafo único do art. 1.864, poderá ser "escrito manualmente ou mecanicamente”.

É de notar que as testemunhas não precisam estar presentes na lavratura do ato, fazendo-se requisito essencial apenas que elas assistam à leitura de todo o testamento, que deverá ser feita a um só tempo. ${ }^{52}$ Apostas as assinaturas logo após a leitura, estará perfectibilizado o ato.

O testamento cerrado ou secreto exige, para que seja válido, a assinatura do testador na própria cédula, enquanto o auto de aprovação deve ser também assinado por este, pelo tabelião e por duas testemunhas (arts. 1.868 e incisos), podendo ser escrito mecanicamente.

Os testamentos marítimo e aeronáutico devem seguir a forma pública ou a cerrada (art. 1.888), de sorte que podem ser feitos mecanicamente. O militar também pode ser cerrado (art. 1.894), pois não há distinção entre este e aqueles, nesse particular, quanto às assinaturas daqueles que devem firmar o testamento. Exige-se, pois, a assinatura do testador, do tabelião, ou do comandante, ou do auditor, ou de quem lhe faça as vezes, conforme o caso, e das testemunhas, permitindose que uma das testemunhas assine a rogo do testador.

Ao seu turno, o testamento particular deve ser escrito e assinado de próprio punho pelo testador e por três testemunhas, bem como poderá ser elaborado por processo mecânico, caso em que devem ser observadas as mesmas exigências quanto à assinatura do disponente e das testemunhas, que igualmente deverão assiná-lo.

É relevante notar que ao cego só se permite o testamento público (art. 1.866), não havendo restrições quanto ao inteiramente surdo, que saiba ler (art. 1.866). Ao surdo-mudo, como visto, é possibilitado testar na forma cerrada, contanto que escreva todo o testamento e o assine de sua mão (art. 1.873). $\mathrm{O}$ analfabeto e quem não possa ler não podem testar na forma cerrada (art. 1.872).

A possibilidade de utilização do meio mecânico na feitura das disposições de última vontade é traço comum de todas as formas testamentárias,

51 GOMES, Orlando. Ob.cit., p. 107.

52 GOMES, Orlando. Ob.cit., p. 109. 
bem como a aposição de assinatura manuscrita ou a rogo, cedendo apenas em hipótese especialíssima que permite ao testador dizer sua última vontade quando em combate ou ferido, no caso do testamento militar.

Tais formalidades extrínsecas são exigidas para cada qual das espécies testamentárias que representam, todavia não se pode perder de vista que essas cautelas, consideradas indispensáveis a garantir a plenitude do ato nos seus efeitos, não passam de exigências vinculadas a esse fim. ${ }^{53}$ "São, em síntese, meios para fins de segurança jurídica" ${ }^{54}$, pois, como ensinava Carlos Maximiliano ${ }^{55}$, o testamento "começa a vigorar quando a boca do disponente já se fechou para sempre”.

Nessa linha, Carlos Maximiliano, no início do século XX, já referia que "a própria ideia de ato de última vontade acha-se, como as demais concepções, subordinada à evolução da coletividade, à cultura contemporânea, no diâmetro da liberdade de dispôr do patrimônio". ${ }^{56}$

Por essas mesmas razões e não se podendo olvidar que o rigor da lei é exatamente para que sejam fielmente cumpridas as disposições de última vontade do falecido, é que Arnaldo Rizzardo também expressou sua preocupação sobre o tema:

Está a matéria regulada com minúcias tais, especialmente em certas modalidades de testamento, que dificulta a generalização ou a maior prática desta espécie de sucessão. Nos tempos atuais, não se justifica a complexidade de regras e fórmulas sacramentais exigidas para dar em testamento, que foram mantidas pelo vigente Código, quando as legislações tendem a simplificar a manifestação de vontade e os procedimentos judiciais. ${ }^{57}$

Para que as disposições testamentárias tenham eficácia, é necessário que a autoridade judicial determine o seu cumprimento, variando apenas os pressupostos legais para tanto, em conformidade com a forma do testamento eleito pelo de cujus. Tal exigência trata-se de regras de direito material, mas que se encontram elencadas no Código de Processo Civil ${ }^{58}$, em seus artigos 1.125 a 1.134, que dizem com a abertura, o registro e cumprimento dos testamentos.

53 GOMES, Orlando. Ob. cit., p. 106.

54 GOMES, Orlando. Ob. cit., p. 106.

55 MAXIMILIANO, Carlos. Ob. cit., p. 417.

56 Ibidem, p. 363.

57 RIZZARDO, Arnaldo. Ob. cit., p. 228.

58 GOMES, Orlando. Ob. cit., p. 126. 
A Lei n. 11.419 de 19 de dezembro de $20066^{59}$ dispôs sobreainformatização do processo judicial, alterando vários dispositivos do Código de Processo Civil, a par de passar a admitir, em seu artigo $1^{\circ}$, o uso de meio eletrônico na tramitação de processos judiciais, na comunicação de atos e transmissão de peças processuais. Determina no mesmo dispositivo que:

$\S 2^{\circ}$ Para o disposto nesta Lei, considera-se:

I - meio eletrônico qualquer forma de armazenamento ou tráfego de documentos e arquivos digitais;

II - transmissão eletrônica toda forma de comunicação a distância com a utilização de redes de comunicação, preferencialmente a rede mundial de computadores;

III - assinatura eletrônica as seguintes formas de identificação inequívoca do signatário:

a) assinatura digital baseada em certificado digital emitido por Autoridade
Certificadora credenciada, na forma de lei específica;

b) mediante cadastro de usuário no Poder Judiciário, conforme disciplinado pelos órgãos respectivos.

A par disso, os artigos $8^{\circ}$ a $13^{\circ}$, dispostos no capítulo III da mesma Lei, disciplinam o processo eletrônico, "prevendo-se o processo sem papel, com autos digitais ${ }^{60}$, em que são considerados originais para todos os efeitos legais os documentos produzidos eletronicamente e juntados aos processos eletrônicos com garantia da origem e de seu signatário" (art. 11, Lei. 11.419/2006).

Nessa ordem de ideias, é certo que estamos diante de um novo tempo, que reclama adaptações, em que o direito material deve consoar com o processual e com o digital, de forma sistemática. Há, modernamente, um novo espaço, o virtual. O sistema jurídico sofre novas leituras. A relação espace-temps, systéme et Droit ${ }^{61}$ ganha novos coloridos e está em constante

59 A Lei 11.419/2001 está dividida em 04 capítulos, sendo que o primeiro versa sobre a informatização do processo judicial, estabelecendo regras para a criação de um sistema de comunicação eletrônica, sendo que esta, especificamente no que diz com a comunicação dos atos processuais, é tratada no segundo capítulo. O terceiro trata do processo eletrônico e prevê a existência de autos total ou parcialmente digitais. Por fim, a informatização do processo judicial vem normatizada último capítulo.

60 CALMON, Petrônio. Comentários à Lei de Informatização do Processo Judicial. Rio de Janeiro : Forense, 2007, p . 49.

61 INTZESSILOGLOU, Nikolaos. L'espace-temps du système juridique : de la spatiotemporalité systèmique à la spatio-temporalité juridique. 1997. 
movimento graças à nova Revolução Tecnológica ${ }^{62}$, que vem alterando as relações humanas, culturais, políticas e econômicas, alcançando a sociedade como um todo.

Acerca da sociedade informática são as nossas próximas considerações.

\section{C) A sociedade informática}

As novas tecnologias da informação e da comunicação ensejam uma releitura do direito posto, bem como a necessidade de compreensão e de verificação de novos direitos. Na nova configuração da sociedade, "a informação já não decorre de um domínio especializado, ela tornou-se um recurso estratégico de base para o conjunto da sociedade, o novo centro do sistema socioeconômico". ${ }^{63}$

Como ensina a Professora Gema Botana Garcia: ${ }^{64}$

Las llamadas nuevas tecnologías de la información incorporan novedades que transforman de forma substancial la economia, las relaciones humanas, la cultura y la politica em nuestra sociedad, lo que permite hablar, incluso, de la primera y más rápida revolución tecnológica global. Esta situación nos lleva a los inicios de una nova era, la de la información y la comunicación, sin precedentes desde ele invento de la imprenta. El progresso teconológico permite processar, almacenar, obtener y comunicar información culaquiera que sea su forma (oral, escrita, o visual) em um modo no limitado por la distancia, el tiempo o el volumen. Puede decir-se, por tanto, que a sociedad de la informción se basa em ele uso generalizado de información de bajo custe, el almacenaje de datos y las tecnologias de transmissión.

No campo das relações humanas, o lazer, v.g., com os jogos eletrônicos, as "conversas" entre as "comunidades" virtuais, as viagens a locais distantes por intermédio do Google Earth $^{65}$ revelam que o "brincar" não

62 SILVEIRA, Sérgio Amadeu da. Exclusão Digital: a miséria na era da informação. São Paulo: Editora Perseu Abramo, 2005, p. 8. O autor refere que a nova revolução tecnológica tem recebido muitas denominações pela doutrina: Revolução das Novas Tecnologias de Informação, Revolução Digital, Revolução Informacional, Era do Acesso, entre outras.

63 HARVEY, Pierre-Léonard. Ciberespaço e comunáutica. Apropriação, redes, grupos virtuais. Tradução de Isabel Andrade. Les Presses de L'Université de Laval, 1995. Instituto Piaget, p. 16.

64 GARCIA, Botana Gema; CARPIO, Badenas. Comércio electrónico y protección de los consumidores. Madrid: La Ley. 2001. Noción e comercio electrónico. p. 5-61.

65 Google Earth. Trata-se de um programa de computador em que é possível chegar a qualquer ponto do planeta, com precisão dos países, cidades, bairros e ruas, pela Internet. 
é o mesmo de outrora, e as crianças aprendem que não podem abrir e-mails de estranhos. A família, agora repersonalizada ${ }^{66}$, ganha novos amigos e traições virtuais. ${ }^{67} \mathrm{O}$ diálogo do grupo familiar diminui entre os próximos, mas há aproximação daqueles que estão, quiçá, do outro lado do mundo.

O ensino é possível a distância, alcançando o saber aos mais remotos pontos do mundo ${ }^{68}$, em que as pessoas podem assistir as aulas sem sair de suas casas. E os professores aprendem que educação digital "não é apenas ensinar como usar os aparatos tecnológicos ou fazer efetivo uso da tecnologia no ambiente escolar. Educar é preparar indivíduos adaptáveis e criativos com habilidades que lhes permitam lidar facilmente com a rapidez na fluência das informações e transformações" ${ }^{69}$

Doenças como a LER - lesão por esforço repetitivo - passam a figurar com singular frequência nos diagnósticos médicos. O tempo de trabalho, estudo e lazer em frente a um computador passa a necessitar de uma melhor administração, pena de sérios prejuízos à saúde, que seguramente serão absorvidos pela própria sociedade, por meio da Previdência Social.

$\mathrm{Na}$ economia e nas relações de trabalho, a expressão em voga é o

66 LÔBO, Paulo Luiz Netto. A Repersonalização das Relações de Família. Direito de Família Contemporâneo e os Novos Direitos: Estudos em Homenagem ao Professor José Russo. Rio de Janeiro: Forense, 2006. p. 99-114. Ensina o autor que “a excessiva preocupação com os interesses patrimoniais que matizaram o direito de família tradicional não encontra eco na família atual, vincada por outros interesses de cunho pessoal ou humano, tipificados por um elemento aglutinados e nuclear distinto: a afetividade. Esse elemento nuclear define o suporte fático da família tutelada pela Constituição, conduzindo ao fenômeno que denominamos repersonalização".

67 PINHEIRO, Daniela. Trair e teclar, é só começar. “A Internet criou uma nova maneira de ser infiel: começa com mensagens, evolui para confidências, logo entra no reino das fantasias sexuais. Quando menos se espera, o marido ou a mulher já estão teclando sem parar com um desconhecido. Mesmo que nunca se transfira para a vida real, a traição machuca do mesmo jeito”. Artigo disponível em: http://veja.abril.com.br/250106/p_076. html. (Acesso em 21 jul. 2008).

68 No Brasil, as bases legais para a modalidade de educação a distância foram estabelecidas pela Lei de Diretrizes e Bases da Educação Nacional (Lei n. 9.394, de 20 de dezembro de 1996, que foi regulamentada pelo Decreto n. 2.494, de 10 de fevereiro de 1998, e o Decreto n. 2.561, de 27 de abril de 1998). Em 3 de abril de 2001, a Resolução n. 1, do Conselho Nacional de Educação, estabeleceu as normas para a pós-graduação lato e stricto sensu.

69 PINHEIRO, Patrícia Peck. Direito digital. 2. ed. São Paulo: Saraiva. 2008, p. 303. 
“comércio eletrônico ${ }^{70}$ " porque não raro as compras diretamente no estabelecimento comercial e o contato físico com o vendedor nem são mais possíveis. ${ }^{71} \mathrm{O}$ "negócio" é a Internet, e o estabelecimento é virtual, onde um "contrato por clique" pode ser firmado em um segundo e trazer o objeto do consumo ao seu destinatário com razoável rapidez e facilidade, sem questionarmos sequer acerca da capacidade do comprador.

Nesse panorama, renovam-se os estudos acerca dos princípios da confiança e da boa-fé, porque agora inseridos em “contexto eletrônico". A máfé, de outro lado, conduz a condutas criminosas antes impensáveis, que passam a ser positivadas. ${ }^{72} \mathrm{~A}$ sociedade precisa de novas formas de prote-

70 SICA, Salvatore. SATANZIONE, Pasquale. Commercio elettronico e categorie civilistiche. Milano: Guiffrè Editore, 2002, p. 3. "Il tema del commercio elettronico ha perso i connotati che sino a qualche tempo fa parevano caratterizzarlo; infatti, dopo l'iliziale 'sorpresa' dei giuristi rispetto alla novità che il fenomeno di Internet presentava, l'argomento ha preso progressivamente piede, facendo segnare una singolare parabola: da materia per 'addetti ai lavori' ad oggetto de amplia divulgacione. Anzi forse, occorre prendere atto che il commercio elettronico, nelle sua molteplici implicazioni, risulta oggi interessato da uma vera e propria, si passi l'espressione, alluvionne informativa".

71 O Estudo sobre Comércio Eletrônico da TIC Domicílios (2007) apontou que: • Quase a metade das pessoas que já utilizaram a Internet declarou ter realizado pesquisas de preço de produtos ou serviços pela rede (45\%) nos últimos 12 meses, demonstrando que a internet já se consolidou como ferramenta para comparação de custos. • A proporção de usuários de comércio eletrônico permaneceu estável entre 2006 e 2007, passando de $11 \%$ para os atuais $13 \%$. A prática do comércio eletrônico cresceu entre indivíduos de maior poder aquisitivo. Na classe A, a proporção de pessoas que realizou compras pela rede passou de $36 \%$, em 2006, para expressivos 52\%, em 2007. • Manteve-se estável o uso do comércio eletrônico entre indivíduos de classe C (8\%), na qual se encontra o maior número de pessoas que já usaram a Internet. Isso indica que o varejo pela rede só deslanchará quando esses internautas passarem a consumir bens e serviços por meio da Internet. - Os produtos mais populares entre os internautas que realizaram compras pela Internet em 2007 foram os equipamentos eletrônicos, como câmeras, telefones celulares e aparelhos de DVD, adquiridos por $41 \%$ dos adeptos do comércio eletrônico. Em segundo lugar, ficaram os eletrodomésticos e produtos para a casa $(27 \%)$, que em 2006 representavam o quinto produto mais consumido pela rede. Disponível em: http://www.cetic.br/usuarios/tic/2007/destaques-comercio-eletronico-tic-2007.pdf. Acesso em 16 jul. 2008.

72 Os novos tipos penais "informáticos" previstos nos artigos 313-A e 313-B do Código Penal brasileiro, acrescentados pela Lei n. 9.983/2000, são um exemplo disso. 
ção aos cibercrimes, e os criminosos já não poderão ir muito longe, porque passíveis de serem rastreados eletronicamente. ${ }^{73}$

O Programa de Governo Eletrôni$\mathrm{CO}^{74}$ ressalta que a Administração Pública deve ser uma vez transparente, célere e eficaz, pelo que as compras por meio eletrônico por meio da modalidade licitatória pregão já fazem parte do ordenamento jurídico. ${ }^{75} \mathrm{O}$ exercício da democracia é pelo voto eletrônico ${ }^{76}$, e o Fisco ${ }^{77}$ alcança a situação econômica dos contribuintes por meio da declaração de imposto de renda pela rede mundial de computadores.

No contexto eletrônico, diz-se que estamos diante de uma "Reforma do Estado". A intensificação do uso de soluções de governo eletrônico pela Administração Pública, sob o

73 O Projeto de Lei n. 1.288/2007 prevê a vigilância com uso de equipamento de rastreamento eletrônico do condenado em regime aberto.

74 “...O que se pretende com o Programa de Governo Eletrônico brasileiro é a transformação das relações do Governo com os cidadãos, empresas e também entre os órgãos do próprio governo de forma a aprimorar a qualidade dos serviços prestados; promover a interação com empresas e indústrias; e fortalecer a participação cidadã por meio do acesso a informação e a uma administração mais eficiente", com o uso das novas tecnologias da informação e da comunicação. Disponível em: http://www. governoeletronico.gov.br/o-gov.br. Acesso em: 19 jul. 2008).

75 A Lei n. 10.520, de 17 de julho de 2002, instituiu, no âmbito da União, Estados, Distrito Federal e Municípios, nos termos do art. 37, inciso XXI, da Constituição Federal, modalidade de licitação denominada pregão, para aquisição de bens e serviços comuns, "utilizando-se recursos de tecnologia da informação", enquanto o Decreto 3.697, de 21 de dezembro de 2000 regulamenta o denominado "pregão eletrônico".

76 A Lei n. 9.504, de 30 de setembro de 1997, estabelece o sistema eletrônico de votação e da totalidade dos votos (arts. 59 a 62). Sobre o tema, Francisco de Assis Sanseverino (Direito Eleitoral. Porto Alegre, 2008, p. 75) anota que "a implantação do sistema eletrônico no Brasil deve ser analisada na perspectiva histórica do sistema eleitoral brasileiro no sentido de efetivar o princípio da 'verdade eleitoral'”.

77 O Decreto n. 6.022, de 22 de janeiro de 2007, instituiu que o "projeto do Sistema Público de Escrituração Digital (Sped) faz parte do Programa de Aceleração do Crescimento do Governo Federal (PAC 2007-2010) e constitui-se em mais um avanço na informatização da relação entre o fisco e os contribuintes. De modo geral, consiste na modernização da sistemática atual do cumprimento das obrigações acessórias, transmitidas pelos contribuintes às administrações tributárias e aos órgãos fiscalizadores, utilizando-se da certificação digital para fins de assinatura dos documentos eletrônicos, garantindo assim a validade jurídica dos mesmos apenas na sua forma digital”. Disponível em: http://www1.receita.fazenda.gov.br/Sped. Acesso em: 21 jul. 2008. 
enfoque jurídico, foi objeto de análise do professor Cesar Santolin: ${ }^{78}$

\begin{abstract}
A intensificação no uso das Tecnologias da Informação (TI) pelo setor público encontra adequada contextualização neste ambiente de "reformar" o Estado [...] evidenciando o liame existente entre as concepções de reestruturação do setor público e o incremento no uso das tecnologias da informação.
\end{abstract}

Todo esse "caldo tecnológico" precisa de rápida resposta estatal, para o que a Lei n. 11.419 de 19, de dezembro de 2006, como referido, trouxe ao ordenamento jurídico brasileiro a informatização do processo judicial, buscando franca adequação às novas exigências sociais.

Acerca do tema, com propriedade, anota o professor Pedro A. Munar

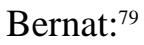

La revolución vivida em el sector de lãs nuevas tecnologias informáticas y de telecomunicacionais há llevado al surgimentos de um nuevo fenômeno que se já venido em denominar "sociedade de La información” y en el que todos nos hallamos inmersos. Uno de sus pirlares há sido el avance en la teconologia que ha permitido la digitalización de la información, lo que possibilita ele almacenamiento de uma gran cantidade y sua desplazimiento em pocos segundos.

Disso decorrem inúmeras outras áreas atingidas pela rede/net, e a informática avança no plano das relações jurídicas públicas e privadas - se é que ainda se pode dizer dessa dicotomia -, em que os documentos são firmados eletronicamente ${ }^{80}$ e a assinatura digital é equiparada à assinatura manuscrita, de próprio punho $^{81}$, o que será objeto de nossa análise nas próximas linhas.

\section{A ASSINATURA DIGITAL}

Como decorrência da evolução da sociedade e do alcance às novas tecnologias da informação e da comunicação, utilizar-se da forma manus-

78 SANTOLIM, Cesar. Aspectos jurídicos do governo eletrônico: as tecnologias da informação na Administração Pública. Revista de Direito de Informática e Telecomunicações - RDIT, Belo Horizonte, ano 2, n. 2, p. 85-97, jan./jun.2007.

79 BERNAT, Pedro A. Munar Bernat. Protección de datos en el comercio electrónico. Coleccíón Biblioteca de Derecho de los Negócios.

80 A Medida provisória n. 2.200-2, de 24 de agosto de 2001, institui a infraestrutura de Chaves Públicas Brasileira - ICP-Brasil. Transforma o Instituto de Tecnologia da Informação em autarquia e dá outras providências.

81 MENKE, Fabiano. Assinatura eletrônica no direito brasileiro. São Paulo: RT, 2005, p. 140. 
crita vem perdendo espaço. As cartas foram substituídas pelos e-mails, de sorte que a Internet restou afastando a necessidade de utilização do suporte de papel para tanto, atendendo inclusive reclamos ambientais. As caligrafias dos interlocutores, não raro, nem são mais conhecidas entre uns e outros, como acontecia ainda no começo deste século.

Nessa linha, como adverte Fabiano Menke ${ }^{82}$ "agora se vive a realidade de, senão de deixar de utilizar totalmente, pelo menos por ter de diminuir bastante a necessidade de utilização das assinaturas manuscritas. E isto de deve justamente ao desenvolvimento da criptografia assimétrica, e, com ela, a criação das assinaturas digitais”. Para que se entendam os conceitos de assinatura digital e certificação digital é necessária a compreensão do que é conceitualmente criptografia, que consoante a lição de Maria Helena Diniz ${ }^{83}$, é "a arte de escrever por meio de códigos ou sinais convencionais”, bem como se trata de "programa que possibilita o acesso à Internet”.

Há dois tipos de criptografia, a simétrica e assimétrica. ${ }^{84} \mathrm{~A}$ primeira guarda registros que remontam às guerras helênicas, na Mesopotâmia e no Egito, estando relacionada aos segredos militares. ${ }^{85}$ Nesta havia a necessidade de que os interlocutores conhecessem previamente o significado dos sinais enviados, que seriam substituídos para decifração da mensagem, de sorte que o código de cifração e de decifração era por ambos conhecidos. A segurança e a praticidade, nessa forma de chaves, restam, todavia, comprometidas no ambiente digital. A criptografia assimétrica ${ }^{86}$,

82 MENKE, Fabiano. Assinatura Eletrônica no Direito Brasileiro. São Paulo: Revista dos Tribunais, 2005, p. 30.

83 DINIZ, Maria Helena, Dicionário jurídico. São Paulo: Saraiva, 1998. v. 1, p. 954.

84 PINHEIRO, Patrícia Peck. Ob. cit., p. 172: “A criptografia é ferramenta de codificação usada para envio de mensagens seguras em redes eletrônicas. É muito utilizada no sistema bancário e financeiro. Na Internet, a tecnologia de criptografia utiliza o formado assimétrico, ou seja, codifica as informações utilizando dois códigos, chamados de chaves, sendo uma pública e outra privada para decodificação, que representam a assinatura eletrônica do documento. Como os números das chaves têm até 2000 algarismos e são produto de complexas operações matemáticas, que permitem trilhões de combinações, os especialistas afirmam que quebrar o sigilo de tal equação é praticamente impossível. A assinatura eletrônica é portanto uma chave privada, ou seja, um código pessoal e irreproduzível que evita os riscos de fraude e falsificação. Para o Direito Digital, uma chave criptográfica significa que o conteúdo transmitido só pode ser lido pelo receptor que possua a mesma chave".

85 MENKE, Fabiano. Ob. cit., p. 44. 
por sua vez, trata-se de técnica para garantia do sigilo e segurança no ambiente digital e consiste em uma utilização de duas chaves, uma pública e outra privada. A chave privada é de uso e domínio do titular da chave da assinatura a ser manejada por meio de um cartão inteligente, que necessita de uma leitora para processamento dos dados nele constantes e pode ser inserida nos teclados dos computadores. A chave pública pode ser divulgada amplamente, sendo certo que ambas as chaves públicas e privadas atuam conjuntamente, uma completando a outra. Assim, o remetente assina sua mensagem utilizando sua chave privada, que será recebida pelo destinatário, que utilizará a chave pública, verificando o reconhecimento da origem do ato.

Mas para conferir maior segurança às comunicações virtuais, em tese, até mais seguras do que as do mundo real, já que a possibilidade de ter uma assinatura manuscrita falsificada é maior ${ }^{87}$, faz-se necessário a agregação de um outro elemento, um terceiro de confiança de ambas as partes, que confira certeza ao destinatário de que quem assinou digitalmente o documento é efetivamente quem se diz ser. ${ }^{88}$ Trata-se dos certificados digitais.

A existência dos certificados digitais é indispensável à garantia da correspondência entre a chave pública e o titular desta. Na lição de Massimiliano Della Torre ${ }^{89}$, "i certificati, in buona sostanza, sono documenti elettronici (files) che contengono informazioni <garantite> circa il titolare della chiave. Esse si dintiguono in elettronici e qualificati, a seconda e del contenuto del certificato e delle qualitá del certificatore". São estruturas de dados sob a forma eletrônica, firmadas digitalmente por uma terceira parte confiável que confere os atributos de uma pessoa a uma chave pública, ${ }^{90}$ que houve identificar anterior e fisicamente o signatário digital, mediante a apresentação dos docu-

86 MENKE, Fabiano. Ob. cit., p. 46. O autor ensina que "a criptografia assimétrica ou chave pública, por seu turno, foi desenvolvida recentemente, a partir de estudos nos anos 70 pelos pesquisadores norte-americanos Whitfledt Diffie, Martin Hellman e Ralph Merkle, considerados inventores dos conceitos de criptografia de chave pública". 87 PINHEIRO, Patrícia Peck. Ob. cit., p. 172.

88 MENKE, Fabiano. Ob. cit., p. 48.

89 TORRE, Massimiliano Della. Diritto e Informatica. Milano: Dott. A. Gurffrè Editore, 2007, p. 83.

90 MENKE, Fabiano. Ob. cit., p. 49. “O fornecimento de um certificado digital é um serviços semelhante ao de identificação para a expedição de uma carteira de identidade, só que o certificado é emitido com prazo de validade determinado. O interessado é identificado mediante a sua presença física pelo terceiro de sua confiança - com a apresentação de documentos necessários - e este lhe emite o certificado digital”. 
mentos pessoais deste, podendo ser titulares de certificados digitais tanto pessoas físicas quanto jurídicas.

A assinatura digital é, assim, espécie de assinatura eletrônica e se trata de instrumento apto a contornar a insegurança do ambiente virtual ${ }^{91}$, o que, no direito brasileiro, veio materializado pelo advento da Medida Provisória n. 2.200-2 de 24 de agosto de 2001, que criou a Infraestrutura de Chaves Públicas Brasileira - ICPBrasil, que estabelece a infraestrutura técnico e administrativa dos agentes que regularão e fornecerão os certificados digitais, bem como "sobre os efeitos jurídicos produzidos por uma declaração de vontade assinada digitalmente com certificado emitido no âmbito da ICP-Brasil, e sobre os efeitos jurídicos emanados de outros meios de comprovação de autoria". ${ }^{22}$

Merece destaque o disposto no artigo 10 da Medida Provisória em comento, que dispõe que "Conside- ram-se documentos públicos ou particulares, para todos os fins legais, os documentos eletrônicos de que trata esta Medida Provisória”, enquanto o parágrafo primeiro estabelece que “As declarações constantes dos documentos em forma eletrônica produzidos com a utilização de processo de certificado pela ICP-Brasil presumem-se verdadeiros em relação aos seus signatários, na forma do art. 131 da Lei n. 3.071 , de $1^{\circ}$ de janeiro de $1916{ }^{\prime}{ }^{93}$

A simples leitura dos precitados dispositivos legais enseja a conclusão de que a autoria dos documentos eletrônicos, assinados digitalmente a partir de chave privada associada à chave pública inserida em certificado digital ${ }^{94}$ obtido no âmbito da ICP-Brasil, será equiparada à assinatura manuscrita, lançada de próprio punho. ${ }^{95}$

Essa situação traz à tona a regra da equivalência funcional ${ }^{96}$, pois "a assinatura eletrônica, e mais concretamente a assinatura digital, possibilita efei-

91 MENKE, Fabiano. Ob. cit., p. 36.

92 Ibidem, p. 99.

93 O art. 219 do Código Civil de 2002 guarda idêntica redação do disposto no art. 131 do Código Civil de 1916: "As declarações constantes de documentos assinados presumem-se verdadeiras em relação aos signatários”, de sorte que as disposições da MP 2.200-2 permanecem inalteradas.

94 A Receita Federal é exemplo de Autoridade Certificadora. Sobre o tema e como obter um certificado digital, consultar: http://www.receita.fazenda.gov.br. Acesso em: 21 jul. 2008.

95 É a exata conclusão de Eduardo Menke, após análise doutrinária acerca do disposto no art. 131 do Código Civil, entre outros aspectos. Ob. cit., p. 136/141.

96 MENKE, Fabiano. Ob.cit.,p. 141. 
tos, senão iguais, até mesmo superiores aos de uma assinatura manuscrita, uma vez que pode proporcional integridade, autenticidade e não repúdio", ${ }^{77}$

A certificação das declarações constantes dos documentos em forma eletrônica produzidos com a utilização de processo de certificado pela ICP-Brasil, todavia, em nada se confunde com a atividade notarial ${ }^{98}$, mas é certo que os cartórios da atualidade podem oferecer serviços de certificação digital. A par disso, é relevante destacar que, no Brasil, já se verifica a existência de cartórios virtuais.

\section{O TABELIONATO VIRTUAL}

Dentre os atos e fatos da vida civil, há aqueles que prescindem de registro; outros, mesmo envolvendo interesses de pessoas determinadas, porque repercutem na vida de um indeterminado número de pessoas, necessitam da intervenção de pública, dada a importância que lhes é conferida pelo legislador. ${ }^{99}$

Nessa linha, a atividade notarial, que consiste precisamente na "administração pública dos interesses pri- vados”100, foi regulamentada pela Lei n. 8.935, de 18 de novembro de 1994 , que, em seu artigo $1^{\circ}$, estabelece que "serviços notariais e de registro são os de organização técnica e administrativa destinados a garantir a publicidade, autenticidade, segurança e eficácia dos atos jurídicos”, a par de prescrever que aos tabeliães de notas compete, com exclusividade, nos termos do art. $7^{\circ}$, "lavrar escrituras e procurações públicas; lavrar testamentos públicos e aprovar os cerrados, lavrar atas notariais, reconhecer firmas e autenticar cópias”.

A função notarial, diz Leonardo Brandelli ${ }^{101}$, citando Pedro Ávila Alvarez, "resume-se na autorização do instrumento público, porém complementada por uma série de atos [...], consiste em receber ou indagar a vontade das partes; assessorá-las como técnico e com isso dar forma jurídica à vontade delas; redigir o escrito que se converterá em instrumento público; autorizar o instrumento público, dando-lhe forma pública e credibilidade; conservar o instrumento autorizado; expedir cópias do instrumento". Tais atividades, em sua essência, não se identificam com a certifi-

97 NADAL, Martinez, apud MENKE, Fabiano. Ob. cit., p. 141.

98 MENKE, Fabiano. Ob. cit., p. 115-116.

99 Nesse sentido, SWENSSON, Walter Cruz (et al.). Leis de Registros Públicos Anotada. São Paulo: Editora Juarez de Oliveira, 2003, p. 1.

100 SWENSSON, Walter Cruz (et al.). Ob. cit., p. 1.

101 BRANDELLI, Leonardo. Ob. cit., p. 119-120. 
cação digital, como referiu Fabiano Menke ${ }^{102}$, mas não se pode olvidar que, atendidos os termos da Medida Provisória n. 2.200-2, poderão também os cartórios oferecer serviços virtuais.

Exemplo disso, e real, é o cartório virtual ${ }^{103}$, que adaptado às condições antes referidas, pode também oferecer certidões digitais ${ }^{104}$, o que, seguramente, aponta o "caminho eletrônico" que será trilhado pelos tabelionatos de notas.

Essa situação permite-nos ponderar se também os atos revestidos de solenidade, como o são os testamentos, poderão ser lavrados por meio eletrônico, atendendo aos preceitos legais e à segurança jurídica, tendo em conta que as assinaturas digitais e manuscritas guardam identidade fun- cional, além de haver previsão legal de formação de autos digitais, sem papel.

Para tanto, ilustramos as seguintes hipóteses:

Em se tratando de testamento público, supondo-se que, enviada eletronicamente a minuta do testamento ${ }^{105}$, poderia o tabelião lavrá-lo digitalmente, o que, aliás, já vem sendo feito. O testamento poderia, então, ser assinado digitalmente pelo testador e, da mesma forma, pelas testemunhas instrumentárias, bem como pelo tabelião. Tudo com a devida certificação digital, a fim de resguardar a autenticidade de todos os envolvidos da realização do ato.

A necessária leitura do testamento em voz alta pelo tabelião ao testador

102 MENKE, Fabiano. Ob. cit., p. 114.

103 Exemplo no Brasil de Cartório virtual pode ser encontrado no site http://www. cartorio24horas.com.br/index.php. "O Cartório 24 Horas objetiva disponibilizar à sociedade o serviço de solicitação de certidões através da Internet a TODOS OS CARTÓRIOS INTEGRANTES DA REDE BRASILEIRA DE CARTÓRIOS, permitindo ao cidadão ou empresa receber suas certidões, de qualquer natureza ou cidade brasileira, no endereço indicado, inclusive no EXTERIOR, com total comodidade, rapidez, segurança e com ótima relação custo x benefício”. Acesso em: 18 jul. 2008.

104 "Trata-se da possibilidade de uma Certidão ser emitida e assinada eletronicamente pelo Cartório, por meio de um 'Certificado Digital' do mesmo. A Certidão terá a mesma validade jurídica, desde que mantida em arquivo eletrônico (a parte requerente da certidão deve aceitá-la em meio eletrônico)". Regulamentação: Medida Provisória n. 2.200-2, de 24 de agosto de 2001. Disponível em: http://www.cartorio24horas.com.br/index.php. Acesso em: 20 jul. 2008.

105 Veja-se que o parágrafo único do artigo 1.864 do Código Civil de 2002 estabelece que "O testamento público pode ser escrito manualmente ou mecanicamente, bem como ser feito pela inserção da declaração de vontade em partes impressas de livros de notas, desde que rubricadas todas as páginas pelo testador, se mais de uma”. 
e às testemunhas poderia, ademais, ocorrer também virtualmente, por meio de videoconferência ${ }^{106}$, o que satisfaria o requisito do inciso II do art. 1.864 do Código Civil, bem como da unidade do ato.

Nesse ponto, é de destacar que o precitado dispositivo legal reclama apenas que o testamento seja lido pelo tabelião na presença do testador e das testemunhas, mas não há nenhuma referência no sentido de que essa "presença" seja física. Tal verificação, ante as novas tecnologias da comunicação e da informação, encontra razão de ser, pois o significado de "pessoa presente" deve agora ser contextualizado, tal como faculta o disposto no art. 428, I, do Código Civil de 2002, que considera presente a pessoa que contrata por telefone "ou por outro meio de comunicação semelhante”. ${ }^{107}$

O testamento cerrado, ao seu turno, observado o regramento do art. 1.868 do Código Civil, poderia contar com o auto de aprovação digital, já que o documento, a rigor, também poderia ser enviado eletronicamente ao tabelião.
O testamento particular, com muito mais razão, poderia ser perfeitamente adaptado ao meio digital, não merecendo maiores considerações, desde que a assinatura do disponente tenha sido também certificada pelo sistema de chaves da ICP-Brasil.

Ainda, algumas pessoas em condições especiais, quiçá, poderiam ser beneficiadas pelo modo eletrônico de testar, observadas as condições de acessibilidade a tanto. Exemplo disso é o surdo-mudo, que poderia utilizar o meio digital para satisfazer a regra do art. 1.873 do Código Civil.

$\mathrm{O}$ arquivo eletrônico em cartório virtual já se faz possível, pelo que a feitura dos atos solenes, e com o devido resguardo da efetiva declaração de vontade das partes, já faz parte da realidade cartorária brasileira.

\section{CONCLUSÃO}

O direito digital, ainda em desenvolvimento, merece especial atenção entre os demais ramos do Direito, em que o público e o privado acom-

106 A Lei n. 11.900, de 8 de janeiro de 2009, dispôs sobre a possibilidade de realização de interrogatório e outros atos processuais por sistema de videoconferência.

107 Acerca do tema, Paulo Lôbo (Direito Civil. Contratos. São Paulo: Saraiva, 2011, p. 94) ensina que "a oferta por meio eletrônico também vincula e deve ser tida como entre presentes, embora o Código Civil a ela não tenha aludido. A mensagem eletrônica (e-mail) é meio semelhante à comunicação telefônica, para fins de oferta, quando se comprova a instantaneidade do envio e do recebimento [...]”. 
panham a evolução da sociedade, sofrendo proporcionais e constantes modificações.

Assim, se a sociedade muda, também o direito deve mudar ${ }^{108}$, porque, a rigor, este espelha aquela. E a questão que se coloca aqui é se o direito sucessório e o instrumental direito notarial deve mesmo mudar, atendendo à influência do direito digital, ou se apenas se faz necessário que essas fontes dialoguem entre $\mathrm{si}^{109}$, na busca das satisfações sociais pós-modernas.

Nesse contexto, o presente estudo busca questionar se as solenidades e formalidades, características do testamento, estariam respeitadas no meio virtual, pois, em suas exigências extrínsecas, é seguro afirmar que as assinaturas manuscritas e digitais guardam identidade funcional.
A par disso, a existência de autos digitais, sem a utilização de papel, passa a ser uma meta da Lei do processo eletrônico. Para que os testamentos tenham eficácia, é necessário que sejam abertos, confirmados e registrados judicialmente, de sorte que utilização do processo eletrônico para tanto pode ser entendida como uma exigência legal.

É certo, nesse contexto, que não se deve temer a possibilidade de falsidades documentais, que sempre existiram na história, mas que a ordem jurídica dispõe de instrumentos capazes de solucioná-las. A própria lei da informatização do processo judicial prevê que "a arguição de falsidade do documento original será processada eletronicamente na forma da lei processual em vigor" ${ }^{\prime 10}$.

\section{REFERÊNCIAS}

AZEVEDO, Álvaro Villaça. Estatuto da Família de Fato. São Paulo: Editora Atlas S.A., 2002.

AZEVEDO, Antonio Junqueira de. O Direito pós-moderno e a codificação. Revista de Direito do Consumidor. São Paulo, v. 9, n. 33, p. 123-129, jan. mar. de 2000.
BRANDELLI, Leonardo. Teoria Geral do Direito Notarial. São Paulo: Saraiva, 2007.

BONFANTE, Pietro. Instituzioni di Diritto Romano. Torino: G. Giappichelli Editore, 1957. CALMON, Petrônio. Comentários à Lei de Informatização do

108 PINHEIRO, Patrícia Peck. Direito digital. 2. ed. São Paulo: Saraiva, 2007. 109 MARQUES, Claudia Lima.

110 Art. 11, § 2º Lei n. 11.419/2006. 
Processo Judicial. Rio de Janeiro: Forense, 2007.

COULANGES, Fustel de. A Cidade Antiga. Trad. de Fernando Aguiar. São Paulo: Martins Fontes, 2000. DINIZ, Maria Helena. Curso de direito civil brasileiro. $6^{\circ}$ volume: direito das sucessões. 21. ed. rev. e atual. de acordo com a Reforma do CPC. - São Paulo: Saraiva, 2007.

Dicionário jurídico. São Paulo: Saraiva, 1998.

FERREIRA, Aurélio Buarque de Holanda. Novo Aurélio Século XXI: O dicionário da língua portuguesa / Aurélio Buarque de Holanda Ferreira. 3.ed. rev. e ampl. Rio de Janeiro: Nova Fronteira, 1999.

GAGLIANO, Pablo Stolze; FILHO, Rodolfo Pamplona. Novo curso de direito civil. São Paulo: Saraiva, 2004

GARCIA, Botana Gema. CARPIO, Badenas. Comércio electrónico y protección de los consumidores. Madrid: La Ley. 2001. Noción e comercio electrónico, p. 5-61.

GILISSEN, John. Introdução Histórica ao Direito. Tradução de A. M. Hespanha e L.M. Malheiros. Lisboa: Fundação Calouste Gulbenkian, 1995

GOMES, Orlando. Sucessões. 14. ed. rev., atual. e aumentada de acordo com Código Civil de 2002 por Mario Roberto
Carvalho de Faria. Rio de Janeiro: Forense, 2008.

LEITE, Eduardo de Oliveira. Direito Civil Aplicado. V. 6: direito das sucessões. São Paulo: Editora Revista dos Tribunais, 2004.

LÔBO, Paulo. Direito Civil. Contratos. São Paulo: Saraiva, 2011.

MARQUES, Claudia Lima, et al. Comentário ao Código de Defesa do Consumidor. São Paulo: Revista dos Tribunais, 2006.

MAXIMILIANO, Carlos. Direito das Sucessões. Rio de Janeiro: Freitas Bastos, 1942.

MENKE, Fabiano. Assinatura Eletrônica no Direito Brasileiro. São Paulo: Revista dos Tribunais, 2005.

NADER, Paulo. Direito da Sucessões. V.6. 2. ed. Rio de Janeiro: Forense, 2008.

OLIVEIRA, Euclides. Direito de Herança. A nova ordem da sucessão. São Paulo: Saraiva, 2005.

OLIVEIRA, Itabaiana. Tratado de Direito das Sucessões. São Paulo: Brasil, 1952.

PINHEIRO, Patrícia Peck. Direito digital. 2. ed. São Paulo: Saraiva, 2007.

PINHEIRO, Daniela. Trair e teclar, é só começar. Disponível em: <http://veja.abril.com. br/250106/p_076.html> Acesso em: 21 jul. 2008. 
RÉGIS. Mário Luiz Delgado. Controvérsias na Sucessão do Cônjuge e do Convivente. Será que Precisamos Mudar o Código Civil. Revista Brasileira de Direito de Família. Porto Alegre: Síntese, IBDFAM. Ano 7. n. 29, p. 191-222, abr.-maio 2005.

RIZZARDO, Arnaldo. Direito das Sucessões. 4. ed. Rio de Janeiro: Forense, 2008.

SANSEVERINO, Francisco de Assis.

Direito Eleitoral. Porto Alegre, 2008.

SANTOLIM, Cesar. Aspectos jurídicos do governo eletrônico: as tecnologias da informação na Administração Pública. Revista de Direito de Infrmática e Telecomunicações - RDIT, Belo Horizonte, ano 2, n. 2, p. 85-97, jan.-jun. 2007.

SANTOS, Luiz Felipe Brasil. Direito das Sucessões - Propostas de Alteração. Revista Brasileira de Direito de Família. Porto Alegre:
Síntese, IBDFAM. Ano 7. n. 29,

p. 185-190, abr.-maio, 2005.

SICA, Salvatore. SATANZIONE, Pasquale. Commercio elettronico e categorie civilistiche. Milano: Guiffrè Editore. 2002.

SILVA, Clóvis Veríssimo do Couto e. O Direito Privado brasileiro na visão de Clóvis do Couto e Silva. Org. Vera Maria Jacob de Fradera. Porto Alegre: Livraria do Advogado, 1997.

SILVA, De Plácido e. Vocabulário Jurídico. 7. ed. Rio de Janeiro: Forense, 1982.

SILVEIRA, Sérgio Amadeu da. Exclusão Digital: a miséria na era da informação. São Paulo: Editora Perseu Abramo, 2005.

SWENSSON, Walter Cruz et al.. Leis de Registros Públicos Anotada. São Paulo: Editora Juarez de Oliveira, 2003.

TORRE, Massimiliano Della. Diritto e Informatica. Milano: Dott. A. Gurffrè Editore, 2007. 